\title{
CCR7 regulates cell migration and invasion through MAPKs in metastatic squamous cell carcinoma of head and neck
}

\author{
FA-YU LIU, JAWAD SAFDAR, ZHEN-NING LI, QI-GEN FANG, \\ XU ZHANG, ZHONG-FEI XU and CHANG-FU SUN \\ Departments of Oromaxillofacial - Head and Neck Surgery and Oral and Maxillofacial Surgery, \\ School of Stomatology, China Medical University, Shenyang, Liaoning 110002, P.R. China
}

Received August 14, 2014; Accepted September 12, 2014

DOI: $10.3892 /$ ijo.2014.2674

\begin{abstract}
Migration and invasion of tumor cells are essential prerequisites for the formation of metastasis in malignant diseases. Previously, we have reported that $\mathrm{CC}$ chemokine receptor 7 (CCR7) regulates the mobility of squamous cell carcinoma of head and neck (SCCHN) cells through several pathways, such as integrin and cdc42. In this study, we investigated the connection between CCR7 and mitogen-activated protein kinase (MAPK) family members, and their influence on cell invasion and migration in metastatic SCCHN cells. Western blotting, immunostaining and fluorescence microcopy were used to detect the protein expression and distribution of MAPKs, and the Migration assay, Matrigel invasion assay and wound-healing assay to detect the role of MAPKs in CCR7 regulating cell mobility. To analyze the correlation between CCR7 and MAPK activity and clinicopathological factors immunohistochemical staining was emplyed. The results showed stimulation of CCL19 and the activation of CCR7 could induce ERK1/2 and JNK phosphorylation, while it had no efect on p38. After activation, ERK1/2 and JNK promoted E-cadherin low expression and Vimentin high expression. The MAPK pathway not only mediated CCR7 induced cell migration, but also mediated invasion speed. The immunohistochemistry results showed that CCR7 was correlated with the phosphorylation of ERK1/2 and JNK in SCCHN, and these molecules were all associated with lymph node metastasis. Therefore, our study demonstrates that MAPK members (ERK1/2 and JNK) play a key role in CCR7 regulating SCCHN metastasis.
\end{abstract}

Correspondence to: Professor Chang-Fu Sun, School of Stomatology, China Medical University, No. 117 Nanjing Bei Jie, Heping District, Shenyang, Liaoning 110002, P.R. China

E-mail: cfsun@mail.cmu.edu.cn

Key words: ERK1/2, JNK, MAPK, CCR7, squamous cancer cells of head and neck

\section{Introduction}

Squamous cell carcinoma of head and neck (SCCHN), a malignant tumor of epithelial origin, represents $>90 \%$ of all head and neck cancers. The 5-year survival rate is only $30-40 \%$ in $\mathrm{SCCHN}$, the main reasons are invasion and metastasis, especially metastasis to lymph nodes (1). The mechanisms leading to SCCHN metastasis are incompletely understood.

Chemokines are a group of small, structurally-related molecules that constitute a superfamily of inducible, secreted, proinflammatory proteins that are involved in a variety of immune responses (2-5). Chemokines are classified into four major groups based on the number and spacing of conserved cysteines: CXC, CC, C and CX3C. The CC chemokine receptor 7 (CCR7) has two ligands: CCL19 and CCL21. The interaction between CCR7 and its ligands promotes the migration, invasion and chemotaxis of $\mathrm{T}$ cells, $\mathrm{B}$ cells, natural killer cells (NK cells), mature dendritic cells (DC) and some tumors (6-9). The tumors affected by this interaction include: esophageal squamous cell carcinoma, colorectal carcinoma, non-small cell lung cancer, hepatocellular cancer, breast cancer, and melanoma (10-15). We have reported that CCR7 regulates cell migration and adhesion in metastatic SCCHN by activating integrin $\alpha v \beta 3$, integrin $\beta 1$ and PI3K/cdc42 (16-24). However, when these downstream molecules are inhibited, the role of CCR7 could not be blocked completely. Thus, we hypothesize there may be other molecules in the CCR7 signal pathway.

Generally, chemokine receptors relay intracellular signals that regulate chemotaxis through the Gi subfamily of $G$ proteins (25). These intracellular signaling molecules include mitogen-activated protein kinase (MAPK) family members (26-28). MAPKs comprise a family of protein-serine/threonine kinases, which are highly conserved in protein structures from unicellular eukaryotic organisms to multicellular organisms, including mammals (29). Mammalian cells contain three major classes of MAPKs: ERK1/2, JNK, and p38. These molecules are important regulators of chemotaxis and/or random motility in a variety of cell types (28,30-32).

We hypothesized that MAPK members may be downstream molecules of the CCR7 pathway induced by CCL19 in SCCHN. The goals of this study were to determine whether MAPK members are activated by CCR7, the role and the 
molecular mechanisms of MAPK in CCR7-regulating SCCHN metastasis.

\section{Materials and methods}

Human tumor samples and cell lines. All clinical investigations were conducted according to the principles expressed in the Declaration of Helsinki. The study protocol was granted approval from the Ethics Committee of the China Medical University, and all participants provided their written informed consent to participate in this study.

SCCHN tissue specimens were obtained from 78 patients by biopsy prior to chemotherapy or radiotherapy at the Department of Oral and Maxillofacial Surgery, School and Hospital of Stomatology, China Medical University. The term 'metastatic' in this study refers to patients with positive lymph nodes that were recognized either at initial presentation or later based on the histopathological diagnosis after neck dissection. The classification of SCCHN, including primary tumors (T), regional lymph nodes $(\mathrm{N})$, distant metastasis $(\mathrm{M})$ and stage grouping, was determined according to the rules of the Union for International Cancer Control (UICC) for head and neck cancer (Tumor node metastasis, TNM classification, 1997). Ten samples of normal tissues adjacent to the benign tumor were chosen as controls.

PCI-4B and PCI-37B, which are well-characterized SCCHN cell lines that are derived from the metastatic lymph node of SCCHN patients, were kindly donated by the University of Pittsburgh Cancer Institute $(33,34)$. The cells were cultured in DMEM medium (Invitrogen Life Technologies, Carlsbad, CA, USA) containing 10\% fetal bovine serum (Gibco, Carlsbad, CA, USA), $100 \mathrm{U} / \mathrm{ml}$ penicillin $\mathrm{G}$ and $100 \mathrm{U} / \mathrm{ml}$ streptomycin. When inhibitors were used, we ensured that the dosage used did not affect the viability or expression of CCR7 of the cells.

Reagents and antibodies. CCL19, CCR7 specific monoclonal antibody (mouse anti-human CCR7 antibody) were purchased from R\&D Systems (Minneapolis, MN, USA), PD98059 (ERK inhibitor) was purchased from Promega Corporation (Madison, WI, USA), SP600125 (JNK inhibitor) was purchased from Biomol GmbH (Hamburg, Germany). The anti-phospho-JNK, anti-JNK, anti-phospho-ERK, anti-ERK, anti-phospho-p38 MAPK, anti-p38 MAPK, anti-E-cadherin and anti-Vimentin were purchased from Cell Signaling Technology, Inc. (Danvers, MA, USA).

Immunohistochemical staining and evaluation. Sections were deparaffinized in xylene for $10 \mathrm{~min}$ and were then rehydrated through graded alcohols. To inhibit endogenous peroxide activity, sections were immersed in $100 \%$ methanol containing $0.3 \%$ hydrogen peroxide for $40 \mathrm{~min}$. Following immersion, sections were put in a microwave oven in a jar filled with $10 \mathrm{mM}$ sodium citrate buffer ( $\mathrm{pH} \mathrm{6.0)}$ for $10 \mathrm{~min}$ and cooled at room temperature. Sections were incubated with normal goat serum for $20 \mathrm{~min}$ and were then incubated with the primary antibody for $1 \mathrm{~h}$. After the incubation period, sections were washed three times with PBS and were then incubated with the linking reagent (biotinylated anti-immunoglobulin; Zymed Laboratories, Inc., South San Francisco, CA, USA) at room temperature for $1 \mathrm{~h}$. After being washed three times with PBS, the sections were incubated with a complex of Avidin DH and biotinlylated enzyme (Zymed Laboratories, Inc.) for $30 \mathrm{~min}$. The sections were again washed three times with PBS and incubated with a medium consisting of an equal volume of $0.02 \%$ hydrogen peroxide and diaminobenzidine tetrahydrochloride (Beijing Zhongshan Golden Bridge Biotechnology Co., Ltd., Beijing, China) for $1 \mathrm{~min}$ in the dark. After chromogen development, sections were washed in water and counterstained with hematoxylin. The stained slides were investigated independently by two pathologists who had no knowledge of the clinical parameters and outcomes. All these cells were scored as negative $(-)(<10 \%$ or no staining), weak positive $(+)(11-50 \%)$, positive $(++)(51-75 \%)$, or strongly positive $(+++)(>75 \%)$.

Western blotting. Cells were harvested in a lysis buffer $(10 \mathrm{mM}$ tris(hydroxymethyl)aminomethane (Tris) $\mathrm{HCl}, \mathrm{pH}$ 7.6, $50 \mathrm{mM}$ $\mathrm{Na}_{4} \mathrm{P}_{2} \mathrm{O}_{7}, 50 \mathrm{mM} \mathrm{NaF}, 1 \mathrm{mM} \mathrm{NaV}{ }_{3} \mathrm{O}_{4}, 1 \%$ Triton $\mathrm{X}-100$ and $1 \mathrm{X}$ protease inhibitor of protein tyrosine phosphatases). Lysates were sonicated for $3 \mathrm{sec}$ and centrifuged at $4^{\circ} \mathrm{C}, 14,000 \mathrm{rpm}$ for $30 \mathrm{~min}$. The supernatant was collected for protein quantification using the Bio-Rad Protein Assay dye reagent (Bio-Rad Laboratories, Richmond, CA, USA). Protein $(50 \mu \mathrm{g})$ was size-fractionated through a $10 \%$ SDS-PAGE gel and transferred onto nitrocellulose filters. The filters were blocked $(1 \%$ non-fat dry milk, $0.1 \%$ Triton X-100, $150 \mathrm{mM} \mathrm{NaCl}, 50 \mathrm{mM}$ Tris ( $\mathrm{pH} 7.5)$ and incubated with the primary antibody, which was diluted to a ratio of 1:1,000. Nitrocellulose filters were incubated with horseradish peroxidase-conjugated secondary antibodies. Bands were visualized using the enhanced chemiluminescence system (Amersham Pharmacia Biotech, Piscataway, NJ, USA) and quantified by scanning densitometry using FlourChem V2.0 software.

Immunostaining and fluorescence microscopy. Cells were fixed in 4\% paraformaldehyde in PBS (10 min at room temperature) and permeabilized with $0.2 \%$ Triton X-100 (10 min at room temperature). Cells were then incubated individually in anti-E-cadherin or anti-Vimentin ( $1 \mathrm{~h}$ at room temperature) and FITC-conjugated immunoglobulins ( $1 \mathrm{~h}$ at room temperature). Cell nuclei were stained by DAPI. Representative fields of cells were photographed by fluorescence microscopy.

Migration assay. Disposable 24-well Transwell inserts with $8 \mu \mathrm{m}$ pore size were run in triplicate in DMEM with $0.5 \%(\mathrm{w} / \mathrm{v})$ BSA. Aliquots of the chemokine CCL19 were added to the lower chamber at a concentration of $500 \mathrm{ng} / \mathrm{ml}$. The inhibitors-pre-treated PCI-4B and PCI-37B cell suspensions $\left(2 \times 10^{5}\right)$ were placed in the top of inserts. After $24 \mathrm{~h}$ of incubation, the cells on the upper surface of inserts were removed with a cell harvester, and the membrane was washed with medium. Cells that penetrated the membrane were fixed with ice-cold methanol, stained with $0.5 \%$ crystal violet, photographed, and counted under the microscope. Mean \pm standard deviation (SD) was recorded for each condition and migration index was calculated based on the control, random migration.

Matrigel invasion assay. Cell invasion was quantified in vitro using Matrigel-coated semipermeable, modified inserts with a pore size of $8 \mu \mathrm{m}$. The analysis of Matrigel invasion assay was performed as described in the migration assay incubated 


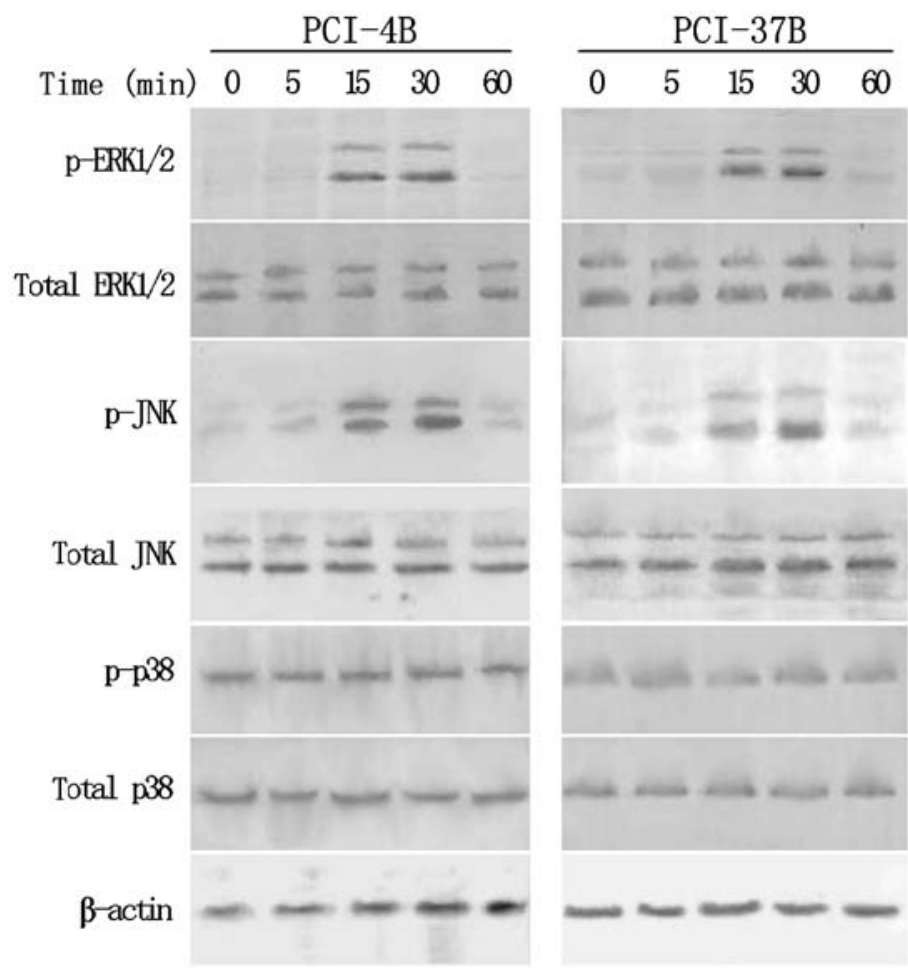

Figure 1. Western blotting of mitogen-activated protein kinase (MAPK) expression induced by CCL19 for different time periods. PCI-4B and PCI-37B cells were treated with CCL19 $(200 \mathrm{ng} / \mathrm{ml})$ for 0-60 min, and MAPK total protein expression and phosphorylation of protein were evaluated. The results are representative of three independent experiments.

with CCL19 for $36 \mathrm{~h}$. Mean \pm SD was recorded for each condition and invasion index was calculated based on the control, random invasion.

Wound-healing assay. SCCHN cells were plated in a 24-well plate at initial density of $1.5 \times 10^{5}$ cells $/ \mathrm{cm}^{2}$. A uniform monolayer formed in 2-3 days. The wounding assays were performed in a serum-free medium. A micropipette tip was used to create a wound in the monolayer by scrapping. The relative cell free area was calculated based on the control group.

Statistical analysis. Data were expressed as the mean \pm SD of repeated assays. The correlation was analyzed using the Spearman's test and $\chi^{2}$ test. Statistical differences between the two groups were evaluated using an unpaired Student's t-test. $\mathrm{P}<0.05$ were considered to be significant. All statistical analyses were performed with SPSS 11.0 software.

\section{Results}

CCR7 stimulates the phosphorylation of ERK1/2 and JNK. MAPK family members (ERK1/2, p38, and JNK) have been implicated in regulating chemotaxis in some systems and random motility in others $(28,30,31)$. Our previous results demonstrated that CCR7 mediated SCCHN cell migration and invasion (17-19). Therefore, we analyzed whether CCR7 induced activation of MAPKs in SCCHN cells. PCI-4B and PCI-37B cells were stimulated with CCL19 for various time periods, then lysed, and the lysates were analyzed by western blotting using antibodies specific for the phosphorylated/active forms and total protein of the three MAPKs.
The results showed that stimulation with CCL19 resulted in a transient and potent phosphorylation of ERK1/2 and JNK, but no effect on p38. Phosphorylation of ERK1/2 and JNK reached a maximum after $15-30 \mathrm{~min}$, and returned to levels close to baseline by $60 \mathrm{~min}$. Total ERK1/2, JNK, p38 and the phosphorylation of p38 had no change under the inducation (Fig. 1).

To further determine whether CCR7 regulates the activation of MAPKs, PCI-4B and PCI-37B cells were pre-treated with CCR7 $\mathrm{mAb}$, the antibody can neutralize the bioactivity of CCR7. Control and CCR7 mAb-treated PCI-4B and PCI-37B cells were stimulated with CCL19, and activation of ERK1/2 and JNK was analyzed. Treatment with CCR7 mAb completely abrogated the CCL19-dependent activation of ERK1/2 and JNK (Fig. 2), indicated that its CCR7 activation stimulates the phosphorylation of ERK1/2 and JNK in SCCHN cells.

To analyze the possible relationship between ERK1/2 and JNK after stimulation of CCR7, we used pharmacological agents. PCI-4B and PCI-37B cells were pre-treated with ERK1/2 inhibitor (PD98059) and JNK inhibitor (SP600125) respectively. The results showed, PD98059 could blunt the increase of the phosphorylation of ERK1/2 induced by stimulation with CCL19, without affecting JNK, and SP600125 could blunt the increase of the phosphorylation of JNK, without affecting ERK1/2, indicating that ERK1/2 and JNK activated independently (Fig. 2).

ERK $1 / 2$ and JNK regulate CCR7-dependent migration and invasion. Our previous results have shown that CCL19 induces PCI-4B and PCI-37B cell migration and invasion, and this can be blocked by CCR7 mAb (17,19) (Figs. 3 and 4). In this 

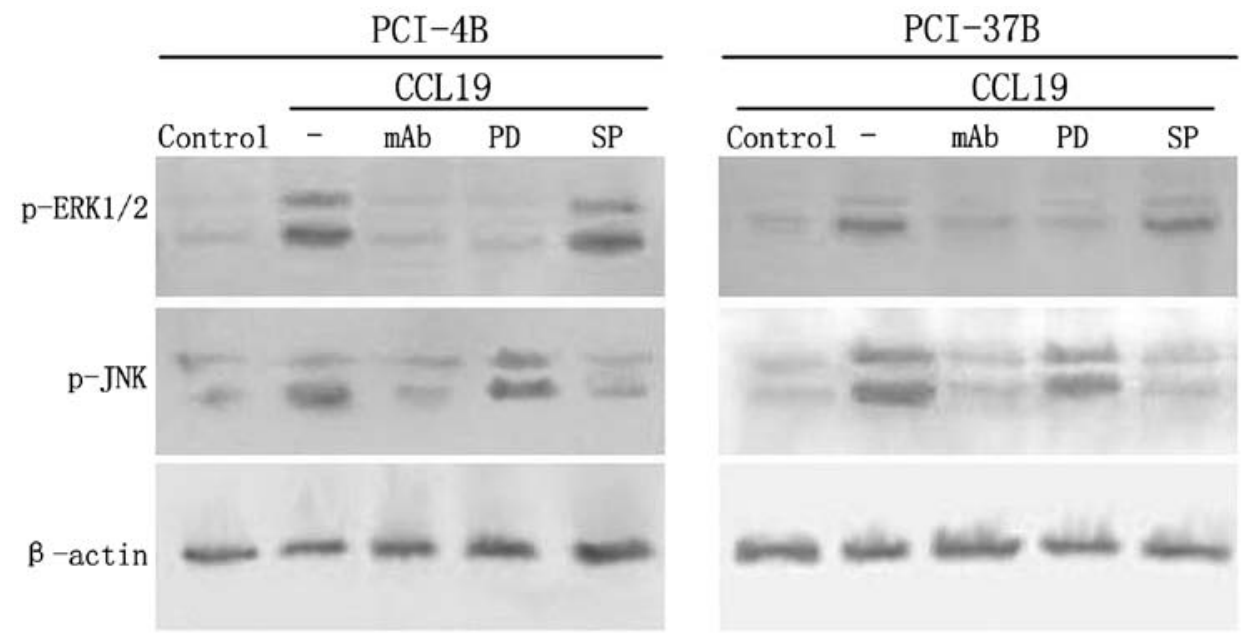

Figure 2. Western blotting of the inhibitors in CCL19 induced ERK1/2 and JNK phosphorylation. PCI-4B and PCI-37B cells were pre-treated with CC chemokine receptor 7 (CCR7) mAb (10 $\mu \mathrm{g} / \mathrm{ml})$, PD98059 $(20 \mu \mathrm{M})$ and SP600125 (50 $\mu \mathrm{M})$ for $4 \mathrm{~h}$, and then CCL19 (200 ng/ml, $30 \mathrm{~min})$. Phosphorylation of ERK1/2 and JNK expression was evaluated by western blotting. The results are representative of three independent experiments.

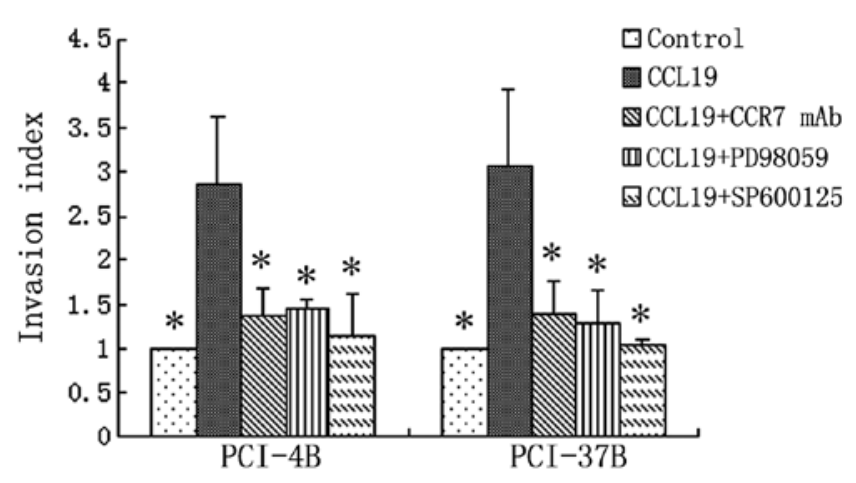

Figure 3. The role of ERK1/2 and JNK inhibitors in CCL19 induced cell invasion. PCI-4B and PCI-37B cells were pre-treated with CC chemokine receptor 7 (CCR7) $\mathrm{mAb}(10 \mu \mathrm{g} / \mathrm{ml}), \mathrm{PD} 98059(20 \mu \mathrm{M})$ and SP600125 $(50 \mu \mathrm{M})$ for $4 \mathrm{~h}$, then CCL19 $(500 \mathrm{ng} / \mathrm{ml}, 36 \mathrm{~h})$. The results are representative of three independent experiments. ${ }^{*} \mathrm{P}<0.05$ compared to CCL19 group.

study, we examined whether ERK1/2 and JNK were involved in regulating the migratory and invasive speed induced by CCR7 activation. The results showed, the cell invasion index induced by CCL19 was almost three times that of the control group, and the inhibition of ERK1/2 and JNK significantly blocked the effect of CCL19 in both cell lines, leading to decreased cell invasion to almost the baseline, as well as CCR7 $\mathrm{mAb}$ (Fig. 3). The migration index was the same as the invasion index. The CCL19 induced migration was significantly blocked by the ERK1/2 and JNK inhibitors (Fig. 4). We also used the wound-healing assay that requires both migration and proliferation of cells. The defined lesions were generated in subconfluent layers of cells and the repopulation of denuded areas was studied. After 12 and $24 \mathrm{~h}$, the gap started to close slowly in the control group, and in the CCL19 group the gap closure was accelerated, and almost merged. After the inhibitor of ERK1/2 and JNK were pre-treated, the cell migration and proliferation decreased significantly, free area was even larger than the control group (Fig. 5). The results indicated that ERK1/2 and JNK regulate CCR7-depedent migration and invasion.

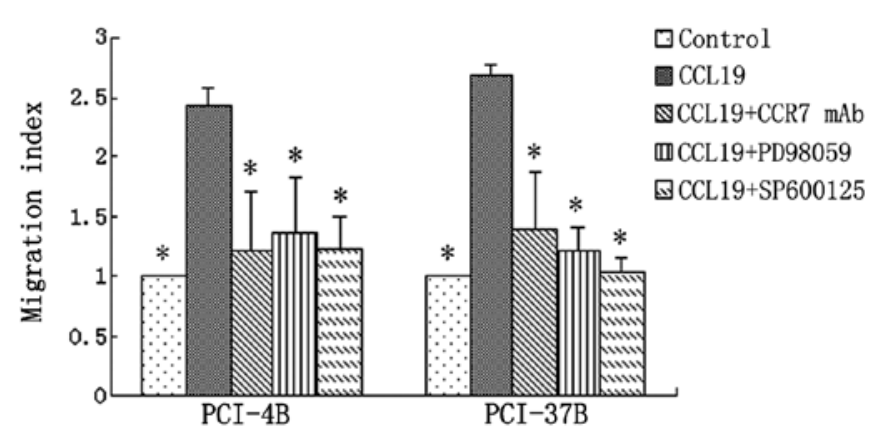

Figure 4. The role of ERK1/2 and JNK inhibitors in CCL19-induced cell migration. PCI-4B and PCI-37B cells were pre-treated with CC chemokine receptor $7(\mathrm{CCR} 7) \mathrm{mAb}(10 \mu \mathrm{g} / \mathrm{ml}), \mathrm{PD} 98059(20 \mu \mathrm{M})$ and $\mathrm{SP} 600125(50 \mu \mathrm{M})$ for $4 \mathrm{~h}$, then CCL19 $(500 \mathrm{ng} / \mathrm{ml}, 24 \mathrm{~h})$. The results are representative of three independent experiments. ${ }^{*} \mathrm{P}<0.05$ compared to CCL19 group.

ERK1/2 and JNK mediate the expression levels of E-cadherin and Vimentin induced by CCR7. CCL19 can induce SCCHN cell migration and invasion. E-cadherin and Vimentin are known to associate with epithelial-mesenchymal transition (EMT), a key point in tumor progress, and to generally participate in migration and invasion. Our results showed that CCL19-treated PCI-4B and PCI-37B cells led to a significant increase in the level of Vimentin protein and a significant decrease in the level of E-cadherin, which can be reversed by CCR7 mAb, implying that CCR7-induced cell migration and invasion may be through E-cadherin and Vimentin expression. After the inhibitor of ERK1/2 and JNK were pre-treated, CCL19-induced high expression of Vimentin was decreased and low expression of E-cadherin was increased (Fig. 6). Combined with previous results, we think ERK1/2 and JNK mediate the expression levels of E-cadherin and Vimentin induced by CCR7, and this pathway may play a key role in SCCHN metastasis.

To demonstrate this conclusions further, we designed an immunofluorescence assay. As Fig. 7 shows, the control cells contacted each other and the immunostaining of E-cadherin 

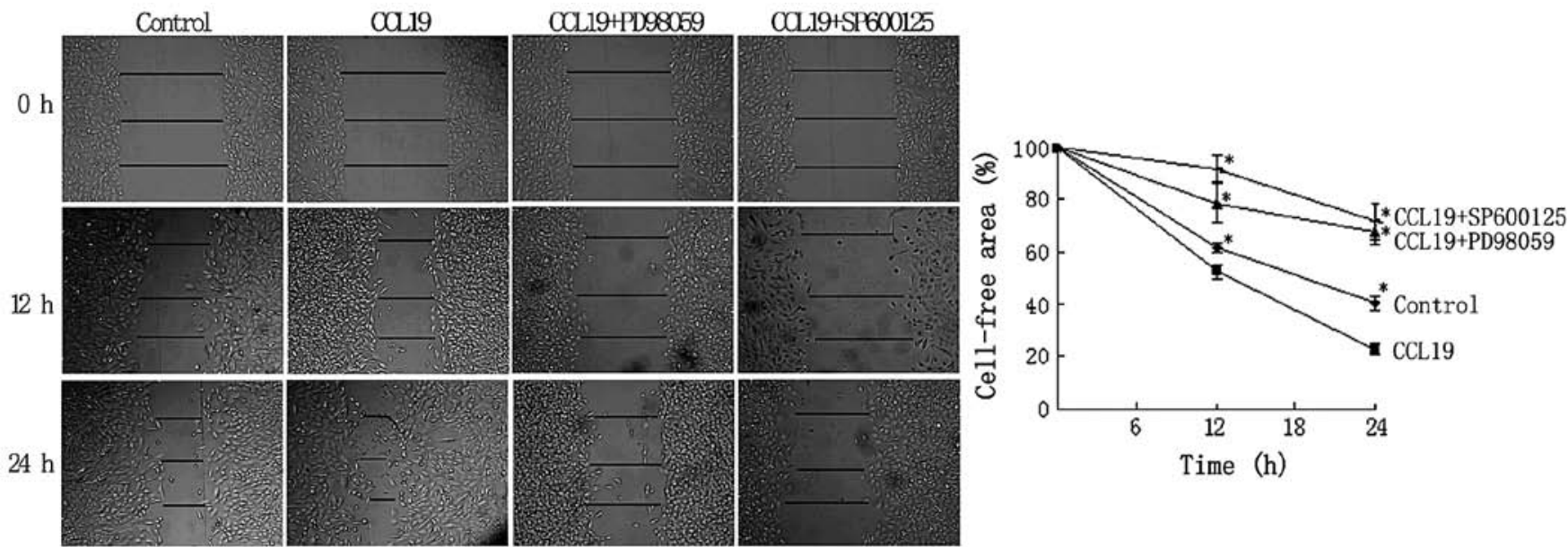

Figure 5. ERK1/2 and JNK inhibitors in CCL19-induced wound-healing. PCI-37B cells were pre-treated with PD98059 (20 $\mu \mathrm{M})$ and SP600125 (50 $\mu \mathrm{M})$ for $4 \mathrm{~h}$, and then CCL19 $(500 \mathrm{ng} / \mathrm{ml})$, the cell free area was evaluated at $0-24 \mathrm{~h}$. The results are representative of three independent experiments. ${ }^{*} \mathrm{P}<0.05$ compared to CCL19 group.
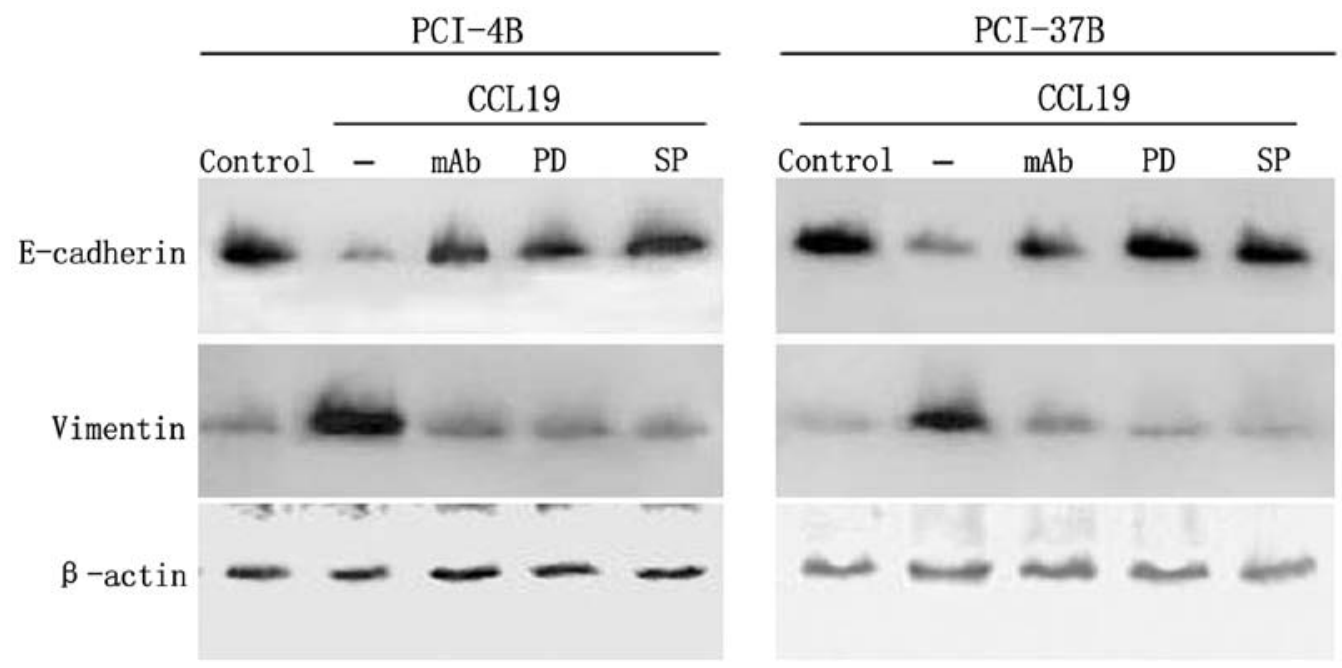

Figure 6. Western blotting of the ERK1/2 and JNK inhibitors in CCL19-induced E-cadherin and Vimentin expression. PCI-4B and PCI-37B cells were pre-treated with CC chemokine receptor 7 (CCR7) mAb (10 $\mu \mathrm{g} / \mathrm{ml})$, PD98059 $(20 \mu \mathrm{M})$ and SP600125 $(50 \mu \mathrm{M})$ for $4 \mathrm{~h}$, and then CCL19 (200 ng/ml, $30 \mathrm{~min})$ E-cadherin and Vimentin expression was assessed by western blotting. The results are representative of three independent experiments.

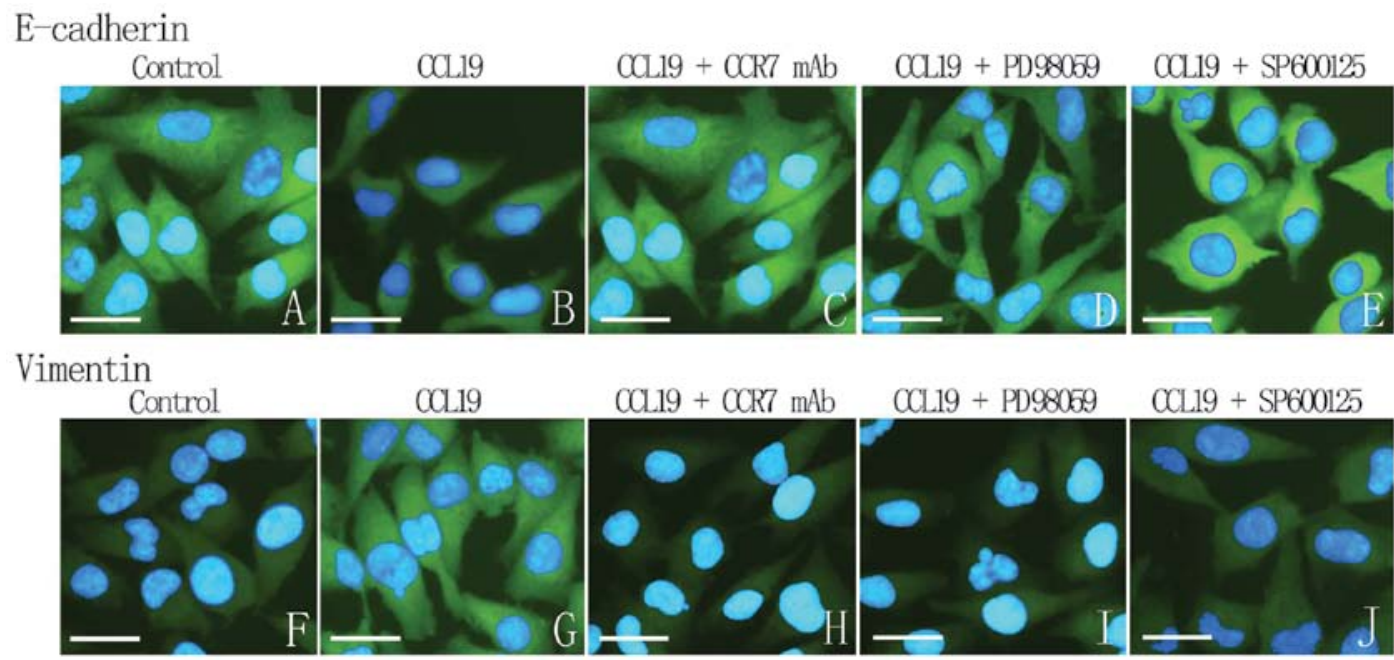

Figure 7. CC chemokine receptor 7 (CCR7), ERK1/2 and JNK in CCL19-induced E-cadherin and Vimentin distribution. PCI-37B cells were pre-treated with CCR7 $\mathrm{mAb}(10 \mu \mathrm{g} / \mathrm{ml})$, PD98059 $(20 \mu \mathrm{M})$ and SP600125 $(50 \mu \mathrm{M})$ for $4 \mathrm{~h}$, and then CCL19 (500 $\mathrm{ng} / \mathrm{ml}, 30 \mathrm{~min})$. E-cadherin and Vimentin distribution was assessed by immunostaining and fluorescence microscopy. The results are representative of three independent experiments. 


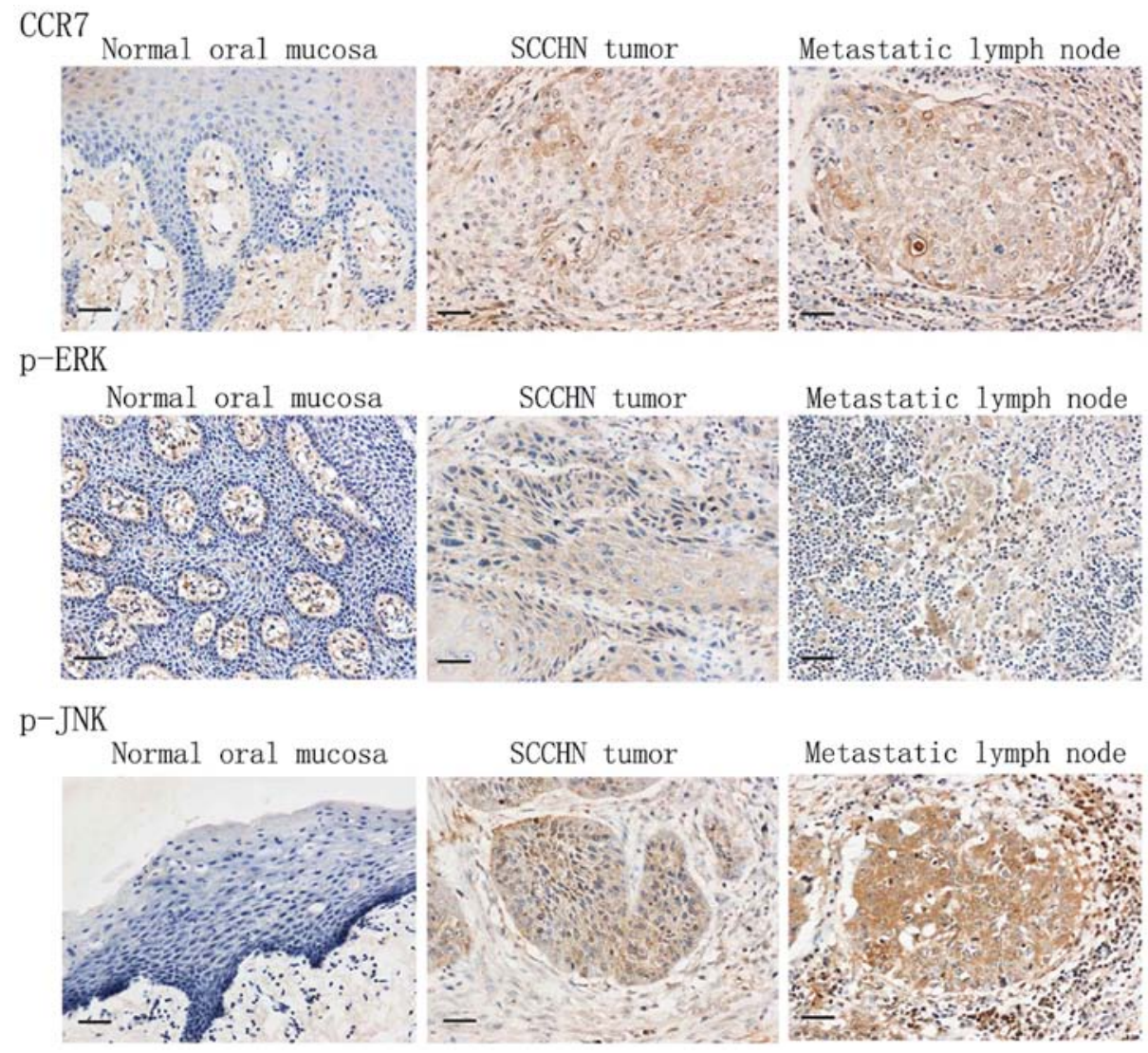

Figure 8. Immunohistochemical staining of CC chemokine receptor 7 (CCR7), ERK1/2 and JNK phosphorylation in normal tissue, squamous cell carcinoma of head and neck (SCCHN) primary tumor, and metastatic lymph nodes.

is very strong. CCL19 group presents no cell-cell contact, and the E-cadherin expression is very low and diffused. When pre-treated with CCR $7 \mathrm{mAb}$, the inhibitors of ERK1/2 or JNK, the E-cadherin expression becomes stronger, although CCL19 induced. On the contrary, control group exhibited diffuse and low cytoplasmic Vimentin staining. In response to CCL19, a network of Vimentin filaments spanning the cell and establishing cell-to-cell contacts was observed. Application of CCR7, ERK1/2 or JNK inhibitor blocked CCL19-induced Vimentin fiber formation and restored the cellular distribution pattern to that under control conditions.

CCR7 and phosphorylation of ERK1/2 and JNK expressed by immunohistochemical staining had significant positive correlation in tumor tissues. Firstly, we studied the expression of CCR7 and phosphorylation of ERK1/2 and JNK in specimens from SCCHN patients by immunohistochemical staining. As Fig. 8 shows, in normal mucosa, CCR7 and phosphorylation of ERK1/2 and JNK were almost not stained. However, CCR7 was strongly immunolocalized in the membrane and the cytoplasm of cancer cells, and phosphorylation of ERK and JNK were detected in the nucleus and the cytoplasm. In metastatic lymph nodes, they were all highly expressed in tumor cells. Of the 78 patients, 48 cases were positive for CCR7 (48/78), and 46 cases were positive for phosphorylation of ERK1/2 (46/78), 41 cases were positive for phosphorylation of JNK (41/78). However, in ten control cases, CCR7, ERK1/2 and JNK phosphorylation was noted only in one case $(1 / 10)$.
SCCHN and normal tissues have significant difference in the expression of CCR7, phosphorylation of ERK1/2 and phosphorylation of JNK $(\mathrm{P}<0.05)$. Table I summarizes the relationship between CCR7 expression, phosphorylation of ERK1/2 and JNK, and the clinicopathological factors of the 78 SCCHN patients. The expression of CCR7, phosphorylation of ERK1/2 and JNK were all significantly correlated with cervical lymph node metastasis and clinical stage $(\mathrm{P}<0.05)$, and had no significant difference with age or gender $(\mathrm{P}>0.05)$. Furthermore, our data also suggested that the phosphorylation of ERK1/2 and JNK was correlated with CCR7 expression, respectively $(\mathrm{P}<0.05)$ (Table II).

\section{Discussion}

Metastasis involves the separation from the primary tumor, migration into the extracellular matrix, blood vessel invasion, adhesion to endothelium and extravasation and growth in a secondary organ (35). Therefore, these steps will regulate cancer cells metastasis. CCL19 is expressed constitutively within lymphoid tissues (36). The interaction of CCR7 and CCL19 promotes cell migration and adhesion in metastatic SCCHN (17-19). However, the mechanisms of adhesion and migration and the signaling pathway involved remains poorly understood.

MAPKs regulate many physiological processes in response to diverse stimuli including cytokines, growth factors, antigens, toxins, drugs, cell shape, adherence to extracellular matrix, and cell-cell interactions. The activation of MAPKs in response to 
Table I. Correlations between CCR7, ERK1/2 phosphorylation, JNK phosphorylation and the clinicopathological factors of SCCHN.

\begin{tabular}{|c|c|c|c|c|c|c|c|c|c|c|}
\hline \multirow{2}{*}{$\begin{array}{l}\text { Clinicopathological } \\
\text { characteristics }\end{array}$} & \multirow{2}{*}{$\begin{array}{l}\text { No. of } \\
\text { cases }\end{array}$} & \multicolumn{2}{|c|}{ CCR7 } & \multirow{2}{*}{$\begin{array}{c}\text { Statistical } \\
\text { analysis } \\
\chi^{2}\end{array}$} & \multicolumn{2}{|c|}{$\begin{array}{c}\text { ERK1/2 } \\
\text { phosphorylation }\end{array}$} & \multirow{2}{*}{$\begin{array}{c}\text { Statistical } \\
\text { analysis } \\
\chi^{2}\end{array}$} & \multicolumn{2}{|c|}{$\begin{array}{c}\text { JNK } \\
\text { phosphorylation }\end{array}$} & \multirow{2}{*}{$\begin{array}{c}\text { Statistica } \\
\text { analysis } \\
\chi^{2}\end{array}$} \\
\hline & & $+\sim+++$ & - & & $+\sim+++$ & - & & $+\sim+++$ & - & \\
\hline \multicolumn{11}{|l|}{ Age } \\
\hline$\geq 60$ & 40 & 25 & 15 & 0.032 & 21 & 19 & 1.422 & 21 & 19 & 0.000 \\
\hline$<60$ & 38 & 23 & 15 & & 25 & 13 & & 20 & 18 & \\
\hline \multicolumn{11}{|l|}{ Gender } \\
\hline Male & 50 & 32 & 18 & 0.357 & 32 & 18 & 1.454 & 23 & 27 & 2.407 \\
\hline Female & 28 & 16 & 12 & & 14 & 14 & & 18 & 10 & \\
\hline \multicolumn{11}{|l|}{ Tumor size } \\
\hline $\mathrm{T} 1, \mathrm{~T} 2$ & 65 & 37 & 28 & 3.510 & 37 & 28 & 0.678 & 29 & 36 & $9.882^{\mathrm{a}}$ \\
\hline $\mathrm{T} 3, \mathrm{~T} 4$ & 13 & 11 & 2 & & 9 & 4 & & 12 & 1 & \\
\hline \multicolumn{11}{|l|}{ Clinical stage } \\
\hline I, II & 37 & 15 & 22 & $13.113^{\mathrm{a}}$ & 17 & 20 & $4.938^{\mathrm{a}}$ & 13 & 24 & $8.575^{\mathrm{a}}$ \\
\hline III, IV & 41 & 33 & 8 & & 29 & 12 & & 28 & 13 & \\
\hline \multicolumn{11}{|l|}{ Nodal metastasis } \\
\hline Yes & 37 & 29 & 8 & $8.434^{\mathrm{a}}$ & 28 & 9 & $8.115^{\mathrm{a}}$ & 24 & 13 & $4.271^{\mathrm{a}}$ \\
\hline No & 41 & 19 & 22 & & 18 & 23 & & 17 & 24 & \\
\hline
\end{tabular}

${ }^{a} \mathrm{P}<0.05$ (the internal difference of CCR7, ERK1/2 phosphorylation or JNK phosphorylation expression within clinicopathological characteristics). CCR7, CC chemokine receptor 7; SCCHN, squamous cell carcinoma of head and neck.

Table II. Correlations between CCR7 expression, ERK1/2 phosphorylation and JNK phosphorylation in SCCHN primary tumor.

\begin{tabular}{|c|c|c|c|c|}
\hline & \multicolumn{2}{|c|}{ ERK1/2 phosphorylation } & \multicolumn{2}{|c|}{ JNK phosphorylation } \\
\hline & $+\sim+++$ & - & $+\sim+++$ & - \\
\hline \multicolumn{5}{|l|}{ CCR7 } \\
\hline$+\sim+++$ & 32 & 16 & 31 & 17 \\
\hline- & 14 & 16 & 10 & 20 \\
\hline
\end{tabular}

CCR7, CC chemokine receptor 7; SCCHN, squamous cell carcinoma of head and neck.

these diverse stimuli contributes to the control of transcription, proliferation, development, cell death, motility, and many other important regulatory responses in cells. To control such diverse biological responses, MAPKs are activated and inactivated with spatial and temporal accuracy within the cell (37). Riol-Blanco et al investigated the intracellular pathways that regulate CCR7-dependent chemotaxis and migratory speed in DCs, and found that CCR7 induced a G(i)-dependent activation of MAPK members ERK1/2, JNK, and p38, with ERK1/2 and p 38 controlling JNK (38). Recently, Shannon et al reported that the CCR7 signaling pathway leading to T-lymphocyte migration on fibronectin is a $\beta 1$ integrin-dependent pathway involving ERK1/2 phosphorylation (39). Our results also showed that, in solid tumor (SCCHN), stimulation of CCL19 and the activation of CCR7 can induce ERK1/2 and JNK phosphorylation, while has no effect on p38, suggesting ERK1/2 and JNK may be the downstream signaling pathway of CCR7 in SCCHN. Furthermore, the phosphorylation of ERK1/2 or JNK did not influence each other, suggesting the two molecules participate in the signaling pathway independently. In DC, ERK1/2, JNK, and p38 only regulated chemotaxis, but not the migratory speed (38), and in B-cell chronic lymphocytic leukemia, ERK1/2 participates in CCL21-dependent migration and invasion simultaneously (40). In our results, ERK1/2 and JNK not only mediated CCR7-induced cell migration, but also mediated the speed of invasion.

MAPKs are members of a three-kinase phosphorylate system composed of the MAPK, MAPK kinase (MKK) and MAPK kinase kinase (MKKK). MKKKs phosphorylate and activate MKKs, which in turn phosphorylate and activate MAPKs. Scaffolding proteins organize MKK-MAPK complexes for activation by specific MKKKs and do so in specific locations in the cell. It is the MKKK associated with the scaffolded complex that provides selectivity for activation by upstream stimuli including GTPases, additional kinases and receptors (41).

The activation of MKK-MAPK complexes regulate the physiological processes by many target proteins. E-cadherin is a transmembrane glycoprotein associated with the cytoskeleton via cytoplasmic proteins. Normal squamous epithelium of the esophagus showed strong E-cadherin/ $\beta$-catenin expression especially on cell-cell boundaries except in the superficial 
layer (42). EMT plays an important role in tumor prognosis, known to dismantle cadherin-medicated cell-cell junctions (43). Thus, disruption of E-cadherin-mediated adhesion is considered as a key step in the progression toward the malignant phase of carcinoma (44). In ovarian cancer, it has been shown that E-cadherin is downregulated by epidermal growth factor (EGF) receptor(EGFR) activation via $38 \mathrm{MAPK}$, and that cells with low E-cadherin expression are particularly invasive (45). In human oral squamous cancer CAL-27 cells, treatment with the ERK inhibitor could also upregulate the expression of the E-cadherin molecule. Vimentin, the major intermediate filament (IF) protein of mesenchymal cells, is also associated with EMT. In lung cancer, transforming growth factor- $\beta 1$-induced EMT was reversed by ERK inhibitor by attenuating the expression of Vimentin (46). In our study, the CCR7-induced ERK and JNK activation downregulated E-cadherin and upregulated Vimentin expression simultaneously, and then affected cell-cell contact and expansion. Therefore, we presumed that E-cadherin and Vimentin are ERK and JNK downstream target molecules in CCR7 regulating SCCHN cell migration and invasion, and this MAPK pathway may generally participate in tumor cells separated from the primary tumor, migrating into extracellular matrix, invading blood vessels and adhering to the endothelium. The immunohistochemistry results not only showed that CCR7 was correlated with the phosphorylation of ERK1/2 and JNK in SCCHN, but also showed that these molecules are all associated with lymph node metastasis. This confirmed the results in vitro.

Taken together, our study supports a hypothesis that CCR7 regulate SCCHN metastasis via MAPK members (ERK1/2 and JNK). However, signaling pathways controlling directional cell migration are not linear, but integrate signals from a plethora of upstream switches into a molecular matrix, resulting in complex cellular responses. Further study is required to elucidate the sequence of events leading to the CCR7-mediated metastatic phenotype, which will enable the development of therapeutic strategies aiming at blocking these carcinogenic and metastatic effects.

\section{Acknowledgements}

This research was supported by grants from the National Natural Science Foundation of China (No. 81372877), the National Young Scholars Science Foundation of China (No. 81102058), the Foundation of Education Bureau of Liaoning Province (No. 2009A755, No. L2014317), the Public Welfare Fund Project for Science of Liaoning Province (No. 2011002001), Natural Science Foundation of Liaoning Province (No. 2014021096), and Excellent Talent Fund Project of Higher Education of Liaoning Province (LJQ2014087).

\section{References}

1. Greenlee RT, Hill-Harmon MB, Murray T and Thun M: Cancer statistics, 2001. CA Cancer J Clin 51: 15-36, 2001.

2. Butcher EC, Williams M, Youngman K, Rott L and Briskin M: Lymphocyte trafficking and regional immunity. Adv Immunol 72 209-253, 1999.

3. Campbell JJ and Butcher EC: Chemokines in tissue-specific and microenvironment-specific lymphocyte homing. Curr Opin Immunol 12: 336-341, 2000.

4. Morales J, Homey B, Vicari AP, et al: CTACK, a skin-associated chemokine that preferentially attracts skin-homing memory $\mathrm{T}$ cells. Proc Natl Acad Sci USA 96: 14470-14475, 1999.
5. Zlotnik A and Yoshie O: Chemokines: a new classification system and their role in immunity. Immunity 12: 121-127, 2000.

6. Mburu YK, Abe K, Ferris LK, Sarkar SN and Ferris RL: Human $\beta$-defensin 3 promotes NF- $\mathrm{KB}$-mediated CCR7 expression and anti-apoptotic signals in squamous cell carcinoma of the head and neck. Carcinogenesis 32: 168-174, 2011.

7. Nagira M, Imai T, Yoshida R, et al: A lymphocyte-specific CC chemokine, secondary lymphoid tissue chemokine (SLC), is a highly efficient chemoattractant for B cells and activated T cells. Eur J Immunol 28: 1516-1523, 1998.

8. Iijima N, Yanagawa Y, Clingan JM and Onoé K: CCR7-mediated c-Jun N-terminal kinase activation regulates cell migration in mature dendritic cells. Int Immunol 17: 1201-1212, 2005.

9. Emmett MS, Lanati S, Dunn DB, Stone OA and Bates DO: CCR7 mediates directed growth of melanomas towards lymphatics. Microcirculation 18: 172-182, 2011.

10. Ding Y, Shimada Y, Maeda M, et al: Association of CC chemokine receptor 7 with lymph node metastasis of esophageal squamous cell carcinoma. Clin Cancer Res 9: 3406-3412, 2003.

11. Takanami I: Overexpression of CCR7 mRNA in nonsmall cell lung cancer: correlation with lymph node metastasis. Int J Cancer 105: 186-189, 2003.

12. Murakami T, Cardones AR and Hwang ST: Chemokine receptors and melanoma metastasis. J Dermatol Sci 36: 71-78, 2004.

13. Gunther K, Leier J, Henning G, et al: Prediction of lymph node metastasis in colorectal carcinoma by expression of chemokine receptor CCR7. Int J Cancer 116: 726-733, 2005.

14. Cabioglu N, Yazici MS, Arun B, et al: CCR7 and CXCR4 as novel biomarkers predicting axillary lymph node metastasis in T1 breast cancer. Clin Cancer Res 11: 5686-5693, 2005.

15. Schimanski CC, Bahre R, Gockel I, et al: Chemokine receptor CCR7 enhances intrahepatic and lymphatic dissemination of human hepatocellular cancer. Oncol Rep 16: 109-113, 2006.

16. Zhao ZJ, Li P, Liu FY, Sun LY and Sun CF: PKC $\alpha$ take part in CCR7/NF- $\kappa$ B autocrine signaling loop in CCR7-positive squamous cell carcinoma of head and neck. Mol Cell Biochem 357: 181-187, 2011.

17. Zhao ZJ, Liu FY, Li P, Ding X, Zong ZH and Sun CF: CCL19-induced chemokine receptor 7 activates the phosphoinositide-3 kinase-mediated invasive pathway through Cdc42 in metastatic squamous cell carcinoma of the head and neck. Oncol Rep 25: 729-737, 2011.

18. Li P, Zhao ZJ, Liu FY, et al: The chemokine receptor 7 regulates cell adhesion and migration via betal integrin in metastatic squamous cell carcinoma of the head and neck. Oncol Rep 24: 989-995, 2010

19. Li P, Liu F, Sun L, et al: Chemokine receptor 7 promotes cell migration and adhesion in metastatic squamous cell carcinoma of the head and neck by activating integrin $\alpha v \beta 3$. Int J Mol Med 27: 679-687, 2011.

20. Liu FY, Zhao ZJ, Li P, Ding X, Zong ZH and Sun CF: Mammalian target of rapamycin (mTOR) is involved in the survival of cells mediated by chemokine receptor 7 through PI3K/Akt in metastatic squamous cell carcinoma of the head and neck. Br J Oral Maxillofac Surg 48: 291-296, 2010.

21. Liu FY, Zhao ZJ, Li P, Ding X and Sun CF: Effect of rapamycin combined with cisplatin on head and neck squamous cancer cells regulated by CCL19. Zhonghua Kou Qiang Yi Xue Za Zhi 46: 197-200, 2011 (In Chinese)

22. Liu FY, Zhao ZJ, Li P, Ding X and Sun CF: The effect of CCL19 on the viability of head and neck squamous cancer cells. Shanghai Kou Qiang Yi Xue 19: 158-161, 2010 (In Chinese).

23. Liu FY, Zhao ZJ, Li P, et al: NF-кB participates in chemokine receptor 7-mediated cell survival in metastatic squamous cell carcinoma of the head and neck. Oncol Rep 25: 383-391, 2011.

24. Liu FY, Zhao ZJ, Huang SH and Sun CF: Role of PDTC in CCL19 regulating the activity of human head and neck squamous cancer cells. J Chin Med Univ 37: 847-849, 2008 (In Chinese).

25. Thelen M: Dancing to the tune of chemokines. Nat Immunol 2: 129-134, 2001.

26. Ganju RK, Brubaker SA, Meyer J, et al: The alpha-chemokine, stromal cell-derived factor-lalpha, binds to the transmembrane G-protein-coupled CXCR-4 receptor and activates multiple signal transduction pathways. J Biol Chem 273: 23169-23175, 1998.

27. Ganju RK, Dutt P, Wu L, et al: Beta-chemokine receptor CCR5 signals via the novel tyrosine kinase RAFTK. Blood 91: 791-797, 1998.

28. Wong MM and Fish EN: Chemokines: attractive mediators of the immune response. Semin Immunol 15: 5-14, 2003.

29. Huang P, Han J and Hui L: MAPK signaling in inflammation-associated cancer development. Protein Cell 1: 218-226, 2010. 
30. Klemke RL, Cai S, Giannini AL, Gallagher PJ, de Lanerolle P and Cheresh DA: Regulation of cell motility by mitogen-activated protein kinase. J Cell Biol 137: 481-492, 1997.

31. Huang C, Rajfur Z, Borchers C, Schaller MD and Jacobson K: JNK phosphorylates paxillin and regulates cell migration. Nature 424: 219-223, 2003.

32. Wang H, Wu C, Wan S, Zhang H, Zhou S and Liu G: Shikonin attenuates lung cancer cell adhesion to extracellular matrix and metastasis by inhibiting integrin $\beta 1$ expression and the ERK1/2 signaling pathway. Toxicology 308: 104-112, 2013.

33. Wang J, Zhang X, Thomas SM, et al: Chemokine receptor 7 activates phosphoinositide-3 kinase-mediated invasive and prosurvival pathways in head and neck cancer cells independent of EGFR. Oncogene 24: 5897-5904, 2005.

34. Mburu YK, Wang J, Wood MA, Walker WH and Ferris RL: CCR7 mediates inflammation-associated tumor progression. Immunol Res 36: 61-72, 2006.

35. Liotta LA, Steeg PS and Stetler-Stevenson WG: Cancer metastasis and angiogenesis: an imbalance of positive and negative regulation. Cell 64: 327-336, 1991

36. Ngo VN, Tang HL and Cyster JG: Epstein-Barr virus-induced molecule 1 ligand chemokine is expressed by dendritic cells in lymphoid tissues and strongly attracts naive $\mathrm{T}$ cells and activated B cells. J Exp Med 188: 181-191, 1998.

37. Johnson GL: Defining MAPK interactomes. ACS Chem Biol 6: $18-20,2011$

38. Riol-Blanco L, Sánchez-Sánchez N, Torres A, et al: The chemokine receptor CCR7 activates in dendritic cells two signaling modules that independently regulate chemotaxis and migratory speed. J Immunol 174: 4070-4080, 2005.
39. Shannon LA, Calloway PA, Welch TP and Vines CM: CCR7/CCL21 migration on fibronectin is mediated by phospholipase Cgamma1 and ERK1/2 in primary T lymphocytes. J Biol Chem 285: 38781-38787, 2010.

40. Redondo-Muñoz J, José Terol M, García-Marco JA, García-Pardo A: Matrix metalloproteinase-9 is up-regulated by CCL21/CCR7 interaction via extracellular signa-lregulated kinase-1/2 signaling and is involved in CCL21-driven B-cell chronic lymphocytic leukemia cell invasion and migration. Blood 111: 383-386, 2008.

41. Johnson GL, Dohlman HG and Graves LM: MAPK kinase kinases (MKKKs) as a target class for small-molecule inhibition to modulate signaling networks and gene expression. Curr Opin Chem Biol 9: 325-331, 2005.

42. Takayama T, Shiozaki H, Shibamoto S, et al: Beta-catenin expression in human cancers. Am J Pathol 148: 39-46, 1996.

43. Savagner P: Leaving the neighborhood: molecular mechanisms involved during epithelial-mesenchymal transition. Bioessays 23: 912-923, 2001.

44. Behrens J: Cadherins and catenins: role in signal transduction and tumor progression. Cancer Metastasis Rev 18: 15-30, 1999.

45. Cheng JC, Klausen C and Leung PC: Hydrogen peroxide mediates EGF-induced down-regulation of E-cadherin expression via p38 MAPK and snail in human ovarian cancer cells. Mol Endocrinol 24: 1569-1580, 2010.

46. Chen XF, Zhang HJ, Wang HB, et al: Transforming growth factor- $\beta 1$ induces epithelial-to-mesenchymal transition in human lung cancer cells via PI3K/Akt and MEK/Erk1/2 signaling pathways. Mol Biol Rep 39: 3549-3556, 2011. 